\title{
The Study on Conservation Status Protection of Minority's Intangible Cultural Heritage
}

\author{
Zhao Hong $^{1, \text { a }}$, Zhao Kun ${ }^{1, b}$ and MaTao ${ }^{1, c}$ \\ ${ }^{1}$ Tianjin Polytechnic University, No 399,Binshuixi Road, Xiqing District, Tianjin, China \\ azhahong300160@126.com, b1392897657@qq.com, ctjpumt@q126.com
}

Keywords: Minority 's Intangible cultural heritage; Protection; The safeguarding way

\begin{abstract}
At present, our country and local governments have made a series of protection work for minority 's Intangible cultural heritage. However, there are also problems such as lack of successors, poor project protection and over-exploitation, Therefore, it is necessary to carry on the inheritance and development through the activation path $(\mathrm{R}-\mathrm{P}-\mathrm{M})$, benefit diffusion and rebuilding path $(\mathrm{M}-\mathrm{P}-\mathrm{R})$ according to the attributes of different minority 's Intangible cultural heritage.
\end{abstract}

At present, the protection work of Intangible cultural heritage in our country is receiving more and more attention. The State Council formulated "state-province-city-county" four-level protection system for Intangible cultural heritage in 2005, and all levels of government and social circles are constantly strengthening the protection of Intangible cultural heritage. It saved many outstanding Intangible cultural heritage projects on the verge of losing. For the protection of minority 's Intangible cultural heritage, the Ministry of Culture has set up 10 experimental zones for national cultural and ecological protection from 2007 to 2015. During development, the Ministry of Culture has provided many valuable experiences for the protection of minority 's Intangible cultural heritage. But at the same time, there are some problems in the regulations, the development scale and so on.

\section{The Status of Occurrence}

Intangible cultural heritage is the crystallization of wisdom of all generations of Chinese people. It encompasses all kinds of cultural forms and related objects and places. Its variety, coverage, and meaning far-reaching are unparalleled. The State Ministry of culture has identified the national level projects as ten categories (see Table 1) when they are determined to work.

Table 1 Ten categorie of national level Intangible cultural heritage

\begin{tabular}{|c|c|c|c|c|c|}
\hline Type & 1 & 2 & 3 & 4 & 5 \\
\hline Folklore & 6 & $\begin{array}{c}\text { Traditional } \\
\text { Music }\end{array}$ & $\begin{array}{c}\text { Traditional } \\
\text { Dance }\end{array}$ & $\begin{array}{c}\text { Traditional } \\
\text { Drama }\end{array}$ & Quyi \\
\hline Type & $\begin{array}{c}\text { Traditional } \\
\text { Sports, } \\
\text { Recreation and } \\
\text { Acrobatics }\end{array}$ & Traditional Art & $\begin{array}{c}\text { Traditional } \\
\text { Crafts }\end{array}$ & $\begin{array}{c}\text { Traditional } \\
\text { Medicine }\end{array}$ & Folk \\
\hline
\end{tabular}

According to statistics, since 2006, the Ministry of Culture has released a total of 1,372 national Intangible cultural heritage in four batches in 2006, 2008, 2011 and 2014 respectively. Among these Intangible cultural heritage, there are 474 minority 's Intangible cultural heritage, accounting for 34.5\% of the total. Due to the diversity of minority 's Intangible cultural heritage, they have been widely distributed in various types of projects. 


\section{Conservation Status}

At present, a series of protection work has been done by the state and local governments and some achievements have been made, including the special protection of the successors, the promulgation of policies and regulations, the establishment of cultural heritage days and the holding of related activities. From a macro perspective, it provide a good environment for protection of minority 's Intangible cultural heritage.

\section{Conservation Status for Successor}

Continue to Strengthen the Funding and Training to o Successor. In recent years, the protection of the successor is positively related to the protection of minority 's Intangible cultural heritage. Especially since 2008, the Central Government started to encourage the successor to carry out related transfer activities and to subsidize the transfer of state-level representative activities. The subsidy rate set at this level is 8,000 yuan / person / year. In 2011, the standard was raised to 10,000 Yuan / person / year. The improvement of this subsidy standard can not only effectively and effectively help the successor encounter difficulties in carrying out the transfer activities, but also well stimulate the enthusiasm and initiative of the successors so that the whole society can guide the protection of the successors effect. At the end of March 2016, the government raised the subsidy standard to 20,000 yuan / person / year.

Set up Seminars and Workshops. At present, there are mainly three ways of inheritance of Intangible cultural heritage, including the mode of seminars and workshops, the way of inheritance among teachers and students, and the method of family inheritance. Pilot training seminars began in 2015 and were jointly launched by the Ministry of Education and the Ministry of Culture. By 2017, as many as 78 colleges and universities have participated in this work. Among them, Tianjin Polytechnic University, Donghua University and so on have been represented. Over 320 training, study and training sessions have been held and 15,000 trainees participated in the training. In addition, the training has been extended throughout the country, covering more than 40,000 peopl.

\section{Other Major Protection Measures}

Issued a Series of Policies and Regulations. Since 2004, our country has successively released a series of laws and regulations on the protection of Intangible cultural heritage. From the state to the ministries and commissions and localities, various laws and regulations are continuously improved. The most worth mentioning is the "Law of Intangible cultural heritage in the People's Republic of China " which adopted by the 11th NPC, which is a turning point in the process of safeguarding the intangible cultural heritage in our country.

Creation of Cultural Heritage Day Activities. In 2005, the State Council promulgated and implemented the "Circular on Strengthening the Protection of Cultural Heritage", demanding that the protection of cultural heritage should be further strengthened and that the "Day of Cultural Heritage" of our country be established on the second Saturday in June of every year. Until to 2016, China has held 11 sessions of Cultural Heritage Day and achieved great success. In September 2016, the State Council decided to set up the "Cultural Heritage Day" as an "Cultural and Natural Heritage Day" from 2017.

Establish National Cultural and Ecological Protection Experimental Zone. For minority 's Intangible cultural heritage, the Ministry of Culture set up 10 experimental zones for the protection from 2007 to 2015 . The experimental area contains many minority 's Intangible cultural heritage .s, as well as a large number of successors. For example, in the experimental area of minority 's Intangible cultural heritage protection in Southeast Guizhou, there are 53 national minority 's Intangible cultural heritage and 192 provincial project. The experimental area can be unified and coordinated development of Intangible cultural heritage, including the use of digital means to memory Intangible cultural heritage, financial subsidies to the representative successors, to strengthen the identification of representative successors and to encourage the opening seminars. 


\section{Existing Problems}

Lack Worthy Successors. Up to now, there are a total of 1986 people in China's four batches of representative national inheritors of intangible cultural heritage, with an average age of over 70 years. Although the Ministry of Culture organized and implemented the rescue recording of representative national-level successors of intangible cultural heritage in order to minimize the tragedy of "death of human beings". However, during the implementation of the rescue record, some elderly heirs will leave the world. Some of the successors, because of their old age, will not be able to show us their skills again for various physical reasons. In addition, there is a phenomenon in which some inheritance projects are unwilling to learn to inherit because the inheritors' treatment is not very high.

Insufficient Protection. The protection of minority 's Intangible cultural heritage needs to be specific to each item and cannot stop at the policy level or remain in the document. However, now the community has its own limitations on the non-heritage heritage. In the process of China's safeguarding of intangible cultural heritage, there is no strict system, norms and standards. The existing traditional methods of collection lack rapid information exchange, norms and safety cannot be guaranteed.

Over Developed. Due to the acceleration of the process of urbanization, some local governments pay more attention to minority 's Intangible cultural heritage to obtain the expected return on their value benefits. Those minority 's Intangible cultural heritage projects with rich investment value and returns will be given priority by local governments to increase the supply of manpower and material resources, The rapid expansion of such projects has become a local feature, stimulating the development of local tourism and stimulating economic growth. However, over-exploitation has added obstacles to the current protection of minority 's Intangible cultural heritage.

Proper Protection but Lack of Benefit. The ultimate goal of protection of minority 's Intangible cultural heritage is not only to continue these outstanding projects, but also to comply with the development of the times and social progress. With the protection and assistance of the government and all sectors of society, these minority 's Intangible cultural heritage can serve the public better, bring tangible benefits to the surrounding areas. It is not uncommon to find effective cases of minority 's Intangible cultural heritage protection for ethnic minorities nowadays, but the real cases of achieving benefits are rare. we should not only protect the coverage of a wide range, but also pay attention to the depth and quality of protection work.

\section{Suggestions}

Based on the analysis of status of protection of minority 's Intangible cultural heritage, the protection pathways can be divided into active path (R-P-M), beneficial diffusion and reconstruction path (M -P -R) according to their fitness measures. Trying to put each minority 's Intangible cultural heritage project into a specific protection path and guide it toward a comprehensive and balanced development of the three elements of resources, product elements and market elements.

Active Path. This method is suitable for minority 's Intangible cultural heritage with good product reputation and high market maturity, but with the strength of resource exploitation, small-scale inheritance and practitioners, single works or deductive forms, etc. For such projects, there is a need to strengthen the genuinely skilled artisans and cultivate more people to work in them, master the essence of traditional skills, enrich product form, create local characteristics, improve market competitiveness, and ultimately expand the market, strengthen tourism and consumption, and promote local economic and cultural development. This will eventually lead to sustainable heritage.

Beneficial Diffusion. This method is suitable for projects which overall developed and inherited better. In order to maintain its sustainable heritage, we can consider the Beneficial diffusion: At the level of maintaining the original inheritance and development level, we should spread the welfare of the development of the intangible heritage to the surrounding industrial and social life, and promote the employment of the surrounding masses and enhance the living standard of the people.

Reconstruction Path. This method is suitable for projects such as fierce market competition, lack of demand or distortion of skills. The reconstruction path ( $\mathrm{M}$ to $\mathrm{P}$ to $\mathrm{R}$ ) is to relocate the market, to develop 
relatively balanced between interests and the traditional technology inheritance, and finally to return to the essence of the intangible heritage projects based on the healthy market, reshaping products and deductive forms.

\section{Acknowledgements}

This paper was supported by the art project of the National Social Science Foundation(17BG135) and the project of Tianjin philosophy and moral science(TJYY16-004 ).

\section{References}

[1] Olimpia Niglio. Inheritance and Identity of Cultural Heritage. Advances in Literary Study, 2014(2)

[2] Kristin Kuutma. Anthropological Perspectives on Intangible Cultural Heritage. Springer-Verlag Publishers, 2013

[3] Zhang Hui. A Review of the Research on the Value of Intangible Cultural Heritage in China in Recent Years. Journal of Honghe University, 2015-08.

[4] Xiao Yuanping, Wang Weijie. Statistical Analysis on the List and Inheritor of the Intangible Cultural Heritage of Chinese Ethnic Minorities. Journal of Southwest University for Nationalities (Humanities and Social Sciences), 2016-01.

[5] Yang Jun. Research on the Protection of Minority's Intangible Cultural Heritage. Journal of South Central University for Nationalities (Humanities and Social Sciences), 2016-01.

[6] SI Juan. The status quo of intangible cultural heritage protection and existing problems. Journal of Yan'an Vocational and Technical College, 2013-06. 